\title{
Venous Thromboembolism Prophylaxis in Critically III Patients
}

\author{
Kochawan Boonyawat, MD ${ }^{1,2}$ Mark A. Crowther, MD² \\ ${ }^{1}$ Department of Medicine, Ramathibodi Hospital, Mahidol University, \\ Bangkok, Thailand \\ 2 Department of Medicine, McMaster University, Hamilton, \\ Ontario, Canada \\ Address for correspondence Mark A. Crowther, MD, Department of \\ Medicine, McMaster University, Hamilton, Ontario, L8N4A6, Canada \\ (e-mail: crowthrm@mcmaster.ca).
}

Semin Thromb Hemost 2015;41:68-74.

\begin{abstract}
Venous thromboembolism (VTE), including deep vein thrombosis (DVT) and pulmonary embolism (PE), is recognized as a common complication in critically ill patients. Risk factors including critical illness, mechanical ventilation, sedative medications, and central venous catheter insertion are major contributing factors to the high risk of VTE. Because of their impaired cardiopulmonary reserve, PE arising from thrombosis in the deep veins of the calf that propagates proximally is poorly tolerated by critically ill patients. Pharmacologic prophylaxis with unfractionated heparin (UFH) or lowmolecular-weight heparin (LMWH) has been shown to decrease the incidence of VTE

Keywords

- venous thromboembolism

- prevention

- critical illness in medical, surgical, and critically ill patients. As a result, over the past decades, VTE prophylaxis had become a standard of preventive measure in the intensive care unit (ICU). In clinical practice, the rate of VTE prophylaxis varies and may be inadequate in some centers. A perception of a high bleeding risk in critically ill patients is a major concern for most physicians that may lead to inadequate prophylaxis.
\end{abstract}

\section{High Risk for VTE in ICU Patients: Role for VTE Prophylaxis}

Critically ill patients are at high risk for the development of VTE. Without VTE prophylaxis the incidence of DVT ranges from 13 to $30 \%{ }^{1,2}$ There is geographic variation in the frequency with which VTE occurs; studies from Asia report a prevalence of VTE in medical-surgical critically ill patients ranging from 6.6 to $10.5 \%,{ }^{3,4}$ slightly less than that reported in Western European and North America.

UFH effectively prevents DVT. ${ }^{5}$ However, a failure rate as high as 5.1 to $15.5 \%$ has been reported. ${ }^{6,7}$ This rate underlines the high risk of VTE in critically ill patients despite anticoagulation. In a prospective cohort study of 261 medicalsurgical ICU patients given UFH 5,000 units subcutaneously bid, DVT developed in $9.6 \%$ of patients during hospitalization. Patients with DVT had a significantly longer duration of mechanical ventilation, ICU stay, and hospitalization than those without DVT. ${ }^{8}$ In a study conducted in Australia and New Zealand including 175,665 critically ill adult patients, omission of thromboprophylaxis within 24 hours of ICU admission was reported to be associated with an increased risk of mortality in critically ill adult patients. ${ }^{9} \mathrm{~A}$ recent observational study, conducted in adult ICU patients in the United States, included 294,896 episodes of critical illness and reported that the group of patients who received prophylactic anticoagulation had a significantly lower risk of death than those not provided VTE prophylaxis. ${ }^{10}$

In summary, critically ill patients have high risk of developing VTE, which may occur despite prophylaxis that is effective in other, lower-risk, settings. VTE in critically ill patients is associated with poorer outcome. These results suggest that VTE pharmacological prophylaxis should be applied to all patients who do not have a contraindication to anticoagulants, and that intensification of anticoagulation may be warranted to further reduce the risk of VTE. published online January 16, 2015
Issue Theme Thrombosis and Hemostasis Issues in Critically III Patients; Guest Editor, Marcel Levi, MD, PhD.
Copyright $\odot 2015$ by Thieme Medical Publishers, Inc., 333 Seventh Avenue, New York, NY 10001, USA. Tel: +1(212) 584-4662.
DOI http://dx.doi.org/ 10.1055/s-0034-1398386. ISSN 0094-6176. 


\section{Pharmacologic Prophylaxis: Evidence-Based Efficacy}

\section{UFH, LMWH versus Placebo}

Evidence of efficacy of UFH or LMWH prophylaxis has been demonstrated in four randomized controlled trials (-Table 1). The first trial of 119 medical-surgical critically ill patients compared UFH 5,000 units subcutaneously twice daily with placebo and showed the risk of screening detected VTE was reduced from 29 to 13\%, a risk reduction of approximately $50 \%{ }^{5}$ The second trial, published only in abstract form, randomized medical ICU patients to UFH 5,000 units subcutaneously twice daily versus placebo. The UFH group had a significant reduction in the rate of DVT compared with the placebo group (11 vs. $31 \%, p=0.001$ ). ${ }^{11}$ The third trial randomized mechanical ventilated patients with chronic obstructive pulmonary disease (COPD) to LMWH (nadroparin $65 \mathrm{U} / \mathrm{kg}$ ) versus placebo. Patients allocated to LMWH had a $45 \%$ reduction in incidence of DVT (15.5 vs. $28.2 \%$, $p=0.045){ }^{12}$ Finally, a subgroup analysis of sepsis patients receiving drotrecogin alfa compared UFH 5,000 units subcutaneously twice daily versus LMWH (enoxaparin) $40 \mathrm{mg}$ subcutaneously daily versus placebo. The rate of symptomatic and asymptomatic lower extremity DVT during days 0 to 6 were not significantly different between three groups (5.6 vs. 4.9 vs. $5.5 \%, 5.1$ vs. 4.0 vs. $4.4 \%$, respectively). ${ }^{13}$

A pooled analysis of outcomes from a recent systematic review and meta-analysis that included the four trials above and found the use of UFH or LMWH compared with placebo was associated with a significantly lower risk of DVT (relative risk $[\mathrm{RR}]=0.51 ; 95 \%$ confidence interval $[\mathrm{CI}]: 0.41,0.63]$, PE $(\mathrm{RR}=0.52 ; 95 \% \mathrm{CI}: 0.28,0.97)$. No difference in the risk of major bleeding or ICU mortality was identified; however, the analysis was underpowered to detect even large differences in rates for these less common outcomes. ${ }^{14}$ These results (which are consistent with those found in other high-risk groups) underscore the significant reduction in VTE in the prophylaxis group and have led, for example, to the 9th American College of Chest Physicians (ACCP) evidence-based clinical practice guideline recommending prophylaxis of critically ill patients with LMWH or low-dose UFH over no prophylaxis. ${ }^{15}$

\section{UFH versus LMWH}

UFH clearance is not dependent on renal function, which is a major advantage over LMWH. A high proportion of critically ill patients have impaired renal function that might limit the use of LMWH. However, LMWH might be preferred in critically ill patients if it demonstrates superior efficacy, and because it has a reduced likelihood of heparin-induced thrombocytopenia, it requires only once-daily administration and is commercially available in a unit dose, reducing the likelihood of medication error ${ }^{16,17}$

Three randomized controlled trials have compared UFH with LMWH for VTE prophylaxis in critically ill patients (-Table 1). The first, a prospective study in 156 surgical

Table 1 Summary of randomized trials demonstrated efficacy of pharmacologic prophylaxis

\begin{tabular}{|c|c|c|c|c|}
\hline \multicolumn{5}{|c|}{ UFH, LMWH vs. placebo } \\
\hline Author & Patient & Intervention & Incidence of DVT (\%) & Sig. \\
\hline Cade $^{5}$ & 119 medical-surgical ICU & $\begin{array}{l}\text { UFH 5,000 units sc bid vs. } \\
\text { placebo }\end{array}$ & 13 vs. 29 & $<0.001$ \\
\hline Kapoor et al ${ }^{11}$ & 791 medical ICU & $\begin{array}{l}\text { UFH 5,000 units sc bid vs. } \\
\text { placebo }\end{array}$ & 11 vs. 31 & 0.001 \\
\hline Fraisse et al $^{12}$ & $\begin{array}{l}223 \text { mechanically ventilated } \\
\text { COPD }\end{array}$ & $\begin{array}{l}\text { LMWH (nadroparin) } 65 \mathrm{IU} / \mathrm{kg} \mathrm{sc} \\
\text { od vs. placebo }\end{array}$ & 15.5 vs. 28.2 & 0.045 \\
\hline Shorr and Williams ${ }^{13}$ & $\begin{array}{l}\text { 1,935 sepsis receiving } \\
\text { drotrecogin alfa }\end{array}$ & $\begin{array}{l}\text { UFH 5,000 units sc bid vs } \\
\text { LMWH (enoxaparin) } 40 \mathrm{mg} \mathrm{sc} \\
\text { od vs. placebo }\end{array}$ & $\begin{array}{l}5.0 \text { vs. } 4.2 \text { vs. } 5.1^{\mathrm{a}} \\
5.6 \text { vs. } 4.9 \text { vs. } 5.5^{\mathrm{b}} \\
5.1 \text { vs. } 4.0 \text { vs. } 4.4^{\mathrm{c}} \\
0.2 \text { vs. } 0 \text { vs. } 0.2^{\mathrm{d}}\end{array}$ & NS \\
\hline \multicolumn{5}{|l|}{ LMWH vs. UFH } \\
\hline De et al $^{18}$ & 156 surgical ICU & $\begin{array}{l}\text { LMWH (enoxaparin) } 40 \mathrm{mg} \mathrm{sc} \\
\text { od vs. UFH 5,000 units sc bid }\end{array}$ & 1.2 vs. 2.7 & NS \\
\hline PROTECT $^{19}$ & 3,764 medical-surgical ICU & $\begin{array}{l}\text { LMWH (dalteparin) } 5,000 \text { units } \\
\text { sc od vs. UFH 5,000 units sc bid }\end{array}$ & $\begin{array}{l}5.1 \text { vs. } 5.8 \\
1.3 \text { vs. } 2.3^{d}\end{array}$ & $\begin{array}{l}\text { NS } \\
0.01\end{array}$ \\
\hline Goldhaber et al ${ }^{20}$ & 310 medical ICU & $\begin{array}{l}\text { LMWH (enoxaparin) } 30 \mathrm{mg} \text { sc } \\
\text { bid vs. UFH } 5,000 \text { units sc bid }\end{array}$ & 25 vs 20 & NS \\
\hline
\end{tabular}

Abbreviations: bid, twice a day; COPD, chronic obstructive pulmonary disease; DVT, deep vein thrombosis; ICU, intensive care unit; LMWH, lowmolecular-weight heparin; NS, not statistically significant; od, once daily; sc, subcutaneous; UFH, unfractionated heparin.

ancidence of any VTE.

bIncidence of symptomatic lower extremity DVT.

'Incidence of DVT by screening ultrasound.

Incidence of PE. 
ICU patients, compared the efficacy of UFH 5,000 units subcutaneously twice daily and LMWH (enoxaparin) $40 \mathrm{mg}$ subcutaneously once daily. There was no significant difference in incidence of DVT (2.66 vs. $1.23 \%) .{ }^{18}$ Owing to small sample size, this study might be underpowered to detect a significant difference. The second trial studied critically ill patients and compared the efficacy of UFH 5,000 units subcutaneously twice daily with LMWH (dalteparin) 5,000 units subcutaneously once daily. There was no significant difference in incidence of DVT; however, in the dalteparin group there was significant lower of incidence of PE (2.3 vs. $1.3 \%, p=0.01){ }^{19}$ This study systematically screened for leg DVT, but all episodes of PE were clinically suspected and confirmed as a component of routine clinical care. The third trial studied medical ICU patients and compared enoxaparin $30 \mathrm{mg}$ subcutaneously twice daily with UFH 5,000 units subcutaneously twice daily. There was no significant difference in DVT rate (25 vs. 20\%). ${ }^{20}$

Pooled outcomes from a meta-analysis reported that LMWH was not associated with a lower risk of DVT when compared with $\mathrm{UFH}(\mathrm{RR}=0.90 ; 95 \% \mathrm{CI}: 0.74,1.08)$, and there was no significant difference seen in the incidence of symptomatic DVT, major bleeding, or ICU mortality in this analysis. $^{14}$ LMWH use was associated with a reduction in asymptomatic PE and symptomatic PE when compared with UFH. There are no direct comparisons between different types of LMWH in critically ill patients.

In summary, current evidence suggests that LMWH might be superior to UFH as it decreases the incidence of symptomatic and asymptomatic PE. These data should be interpreted with caution because they are driven by one large study. Further trials are needed to confirm this benefit of LMWH.

\section{New Anticoagulants}

Recently a series of oral, highly effective antithrombotic medications have become available. These agents have been shown effective for primary and secondary prevention of venous thrombosis and stroke and systemic embolization in patients with atrial fibrillation. ${ }^{21-24}$ However, two large studies in seriously ill medical patients failed to demonstrate net benefit of these medications over LMWH. ${ }^{25,26}$ This evidence, coupled with the need for oral administration, renal dependency with some of the agents, and the lack of effective reversal agents, suggests that these new agents will have little or no role in VTE prophylaxis in critically ill patients.

\section{What Is the Role of Pharmacological Prophylaxis in Critically III Patients with a High Bleeding Risk?}

Despite their high risk for VTE, critically ill patients are also at high risk of bleeding due to their comorbidities, admitting illness (es), and the use of multiple medications and interventions that may cause hemorrhage. Despite this, in one meta-analysis there was no evidence that pharmacologic prophylaxis increased the risk of major bleeding when heparin prophylaxis was compared with placebo. ${ }^{14}$ A large observational study using data from
International Medical Prevention Registry on Venous Thromboembolism (IMPROVE) assessed in-hospital bleeding risk in acutely ill medical patients. Three factors were associated with a high bleeding risk: active duodenal ulcer, bleeding within the 3 months before admission, and platelet count less than $50 \times 10^{9}$ cells/L. Admission to the ICU/coronary care unit (CCU) also contributed to bleeding risk. ${ }^{27}$

In day-to-day clinical practice the risk of bleeding and thrombosis will have to be weighed in an individual patient when selecting the type of anticoagulant prophylaxis. In patients with a sufficiently high bleeding risk, mechanical prophylaxis should be considered, and when the bleeding risk decreases, we suggest resuming pharmacologic thromboprophylaxis.

\section{Is Mechanical VTE Prophylaxis Effective?}

Mechanical prophylaxis including graduated compression stocking (GCS) and intermittent pneumatic compression devices (IPC) is indicated in patients who have a contraindication to pharmacologic prophylaxis. GCS generally seems to be less effective than pharmacologic prophylaxis ${ }^{28}$ and whether they provide significant benefit as VTE prophylaxis, particularly in high-risk patients, remains unclear. ${ }^{29}$ IPC has more evidence to support its efficacy. Three recent randomized controlled trials have been published. The first trial was conducted in medically critically ill patients in which one group received IPC prophylaxis and another received none, with both groups having received no anticoagulation. The IPC group had significantly reduced DVT (3.8 vs. $19.28 \%, p<0.01$ ), PE (0 vs. 9.64\%, $p<0.01$ ), and non-sudden cardiac death ( 1.26 vs. $7.23 \%, p<0.01$ ). ${ }^{30}$ The second trial was conducted in 798 ICU patients and compared the efficacy of GCS, and IPC combined with either UFH or LMWH. IPC use was associated with a significant reduction in VTE (4.8\%) compared with no mechanical prophylaxis (7.2\%) or with GCS (10\%). ${ }^{31}$ The third study randomized ICU patients to IPC plus GCS or GCS alone. There was no significant difference (5.6 vs. 9.2\%) in DVT rate between the two groups; however, the large numerical difference suggests that the comparison was underpowered to detect large differences in event rates. ${ }^{32}$

In summary, IPC decreased the rate of VTE in the setting of ICU patients compared with no mechanical prophylaxis, but less is known about the effectiveness of GCS compared with other prophylaxis strategies.

\section{Inferior Vena Cava Filters}

Inferior vena cava (IVC) filters are indicated in patients who have an absolute contraindication to anticoagulants and who have an active DVT, or PE with evidence of thrombosis below the level of the IVC at which the filter will be inserted. Data from a randomized controlled trial that allocated patients to anticoagulation alone, or anticoagulation plus filter placement, found reduced PE, but no difference in mortality. ${ }^{33}$ In long-term follow-up, patients with IVC filters (with varying exposure to anticoagulants) had an increased risk of recurrent DVT. ${ }^{34}$ Although widely used for VTE prophylaxis, there is no evidence that filters are effective in this setting, and they are 
known to have complications including DVT and IVC thrombosis with potential extension into the renal veins, fracture, strut perforation, and embolization, they are expensive, and they are rarely removed $(<10 \%$ of the time in one recent survey). ${ }^{35}$ IVC filters should not be used for DVT prophylaxis in any critically ill patient. If patients cannot receive pharmacologic prophylaxis due to bleeding or other reasons and IPC cannot be used for prophylaxis, the patient should be monitored with serial ultrasonography and treatment with an IVC filter if DVT is seen.

\section{Thromboprophylaxis Compliance and "Real- World Use" of VTE Prophylaxis}

Compliance with VTE prophylaxis in medical ICU patients is variable, and highly center dependent. Recent studies suggested prophylaxis administration rates of 33\% in medical ICUs, ${ }^{36} 63$ to $86 \%$ in medical-surgical ICUs, ${ }^{37,38}$ and $86.7 \%$ in surgical ICU. ${ }^{39}$ In one prospective, multicenter, point prevalence survey in Australia and New Zealand in hospitalized ICU patients 431/502 (86\%), patients were given VTE prophylaxis. Of those given prophylaxis, $20 \%$ were given only pharmacologic prophylaxis (UFH $74 \%$, enoxaparin $23 \%$ ), $36 \%$ only mechanical prophylaxis, and $44 \%$ both. ${ }^{40}$

In a multicenter, observational study in medical ICU/CCU patients in China including 1,247 patients who had one or more VTE risk factors and excluding patients with the presence of predefined potential risk factors for bleeding, $49 \%$ of patients received at least one type of pharmacologic prophylaxis. Interestingly, antiplatelet drugs were the most commonly used form of pharmacologic prophylaxis. Only $20.2 \%$ of patients received an ACCP recommended VTE prophylaxis strategy. ${ }^{41}$

A small prospective study in Saudi Arabia demonstrated the effect of implementation of a clinical practice guideline on prophylaxis use in medical ICU patients. Use of the guideline in 104 patients resulted in compliance of $98 \%$ with UFH prophylaxis and an incidence of screening detected DVT of $9.6 \%{ }^{42}$

In a multinational observational study in Asia including 2,969 medical ICU patients, 98\% received some form of VTE prophylaxis. Prophylaxis consisted of mechanical prophylaxis in $22.9 \%$, pharmacologic prophylaxis in $31.2 \%$, and both mechanical and pharmacological in $44.2 \%$. The major reasons cited for nonuse of prophylaxis was perceived bleeding risk (52.1\%), low-risk of VTE (27.6\%), and early immobilization (10.3\%). Overall $80.6 \%$ of patients receive VTE prophylaxis according to the ACCP guideline, and $4.7 \%$ per Japanese guidelines. ${ }^{43}$

In a single-point prevalence survey conducted in Japan, 470 patients were admitted to a medical-surgical ICU and a VTE prophylaxis compliance rate of $85.3 \%$ was observed. Of these patients, $69.8 \%$ were given only mechanical, $12.5 \%$ only pharmacologic, and $17.7 \%$ both mechanical and pharmacologic VTE prophylaxis. From this study, hospitals using standardized prevention protocols have significantly better compliance rates than those not having such protocols (88.8 vs. $80 \%, p<0.01){ }^{44}$

Another point prevalence survey conducted in Spain, using an electronic questionnaire in medical, surgical, and major trauma critical care units enrolled 777 patients, $81 \%$ of whom were given VTE prophylaxis (63\% pharmacologic prophylaxis only, $12 \%$ mechanical only, and $6 \%$ both). No VTE prophylaxis was given to $19 \%$ of the patients. ${ }^{45}$

In a large observational study of 294,896 hospital discharges from adult ICUs in the United States, 93\% of patients admitted to medical-surgical ICUs received VTE prophylaxis (27\% anticoagulant only, $34 \%$ mechanical only, and 32\% both). ${ }^{10}$

In summary, almost all recent studies have demonstrated that more than $80 \%$ of critically ill patients receive appropriate VTE prophylaxis (-Table 2). Low prophylaxis rates are attributable to fear of bleeding and low (and probably underestimated) perceived risk of VTE.

Strategies to improve compliance include continual education strategies for physicians. A two-phase 1-year study examined the effect of an educational program on implementation of DVT prophylaxis in surgical-trauma ICU patients. Phase 1 was retrospectively examined the "historical" rate of VTE prophylaxis. Phase 2 was a prospective study after completion of a 1-year of educational program. Compared with the retrospective data, the incidence of DVT after the education program had declined significantly (11.9 to $4.5 \%, p<0.01){ }^{46}$

Another three-phase prospective longitudinal observational study has been reported in medical-surgical ICU. The primary outcome of study was to assess the number of patients on heparin prophylaxis after using a multiple method approach. Phase 1 was a 3-month documented baseline of VTE prophylaxis and phase 2 was a 1 -year period using a multiple-method approach to implement thromboprophylaxis. The method included interactive multidisciplinary educational in-services, verbal reminders to ICU team, computerized daily nurse recording of thromboprophylaxis, weekly graphic feedback, and publicly displayed graphic feedback on group performance. Phase 3 was a 3-month follow-up period 10 months later that examined computerized recording of thromboprophylaxis. The proportion of ICU days during which heparin prophylaxis was administered was significantly increased from $60.0 \%(0,100)$ in phase 1 to $90.9 \%(50,100)$ in phase 2 and $100 \%$ in phase $3(p<0.01) .{ }^{47}$

A study reported measurable outcomes and 2-year-sustainability of a quality improvement program in a surgical ICU, using a daily quality round checklist (QRC). ${ }^{48}$ For this study, a cost-effective QRC was established as a tool to improve the compliance rates with prophylactic measures and to improve outcomes. ${ }^{49,50}$ The checklist is composed of 22 data points and 16 preventive measures including DVT prophylaxis. During a 2-year program with routine implementation of the QRC, overall DVT prophylaxis compliance was $98 \%$.

Electronic reminders are another strategy to improve adherence with VTE prophylaxis. A study randomized 2,506 hospitalized patients to an intervention group that used a computer program linked to a patient database that identified and alerted the physician if the patient was at risk of developing DVT, and compared these patients with a control group. In the intervention group, more patients received mechanical prophylaxis (10 vs. $1.5 \%, p<0.001$ ) and pharmacologic prophylaxis (23.6 vs. $13 \%, p<0.001$ ). 
Table 2 Summary of recently trials demonstrated VTE thromboprophylaxis compliance

\begin{tabular}{|c|c|c|c|c|c|c|}
\hline \multirow[t]{2}{*}{ Author } & \multirow[t]{2}{*}{ Study design } & \multirow[t]{2}{*}{ Patient } & \multicolumn{4}{|c|}{ Rate of VTE prophylaxis (\%) } \\
\hline & & & Pharmacologic & Mechanical & Both & Overall \\
\hline Roberson et al ${ }^{40}$ & $\begin{array}{l}\text { Point prevalence } \\
\text { survey }\end{array}$ & $\begin{array}{l}502 \text { ICU patients in Australia and } \\
\text { New Zealand }\end{array}$ & 20 & 36 & 44 & 86 \\
\hline Ge et $\mathrm{al}^{41}$ & Cross-sectional & $\begin{array}{l}1,247 \text { ICU/CCU patients } \\
\text { in China }\end{array}$ & $49^{a}$ & 13.3 & NM & $20.2^{b}$ \\
\hline Al-Otair ${ }^{42}$ & Prospective study & $\begin{array}{l}104 \text { medical ICU patients in Saudi } \\
\text { Arabia }\end{array}$ & NM & NM & NM & 98 \\
\hline Parikh et $\mathrm{al}^{43}$ & Cross-sectional & 2,969 medical ICU patients in Asia & 31.2 & 22.9 & 44.2 & $\begin{array}{l}80.6^{b} \\
4.7^{c}\end{array}$ \\
\hline $\begin{array}{l}\text { Yamamoto } \\
\text { et } \mathrm{al}^{44}\end{array}$ & $\begin{array}{l}\text { Point prevalence } \\
\text { survey }\end{array}$ & $\begin{array}{l}470 \text { medical-surgical ICU patients } \\
\text { in Japan }\end{array}$ & 12.5 & 69.8 & 17.7 & 85.3 \\
\hline $\begin{array}{l}\text { Garcia-Olivares } \\
\text { et } \mathrm{al}^{45}\end{array}$ & $\begin{array}{l}\text { Point prevalence } \\
\text { survey }\end{array}$ & $\begin{array}{l}777 \text { medical-surgical-trauma- ICU } \\
\text { patients in Spain }\end{array}$ & 63 & 12 & 6 & 81 \\
\hline Lilly et al ${ }^{10}$ & $\begin{array}{l}\text { Observational } \\
\text { cohort }\end{array}$ & $\begin{array}{l}\text { 294,896 hospital discharge from } \\
\text { ICU in United States }\end{array}$ & 27 & 34 & 32 & 93 \\
\hline
\end{tabular}

Abbreviations: ICU/CCU, intensive care unit/coronary care unit; NM, not mention; VTE, venous thromboembolism.

${ }^{a}$ Receiving one or more types of VTE prophylaxis including antiplatelet, traditional Chinese medicine.

${ }^{\mathrm{b}}$ According to ACCP guideline.

'According to Japanese guideline.

The computer alert also reduced the risk of symptomatic DVT or PE at 90 days by $41 \%{ }^{51}$

Another study used electronic reminders added to the electronic medical record in medical, surgical, and ICU patients. The control group enrolled 2,888 patients and recorded baseline VTE prophylaxis in the 6 months prior to implementation of the intervention. In the intervention group of 2,350 patients, the rate of appropriate prophylaxis was significantly increased ( 42.8 vs. $60.0 \%, p<0.001$ ). Fewer patients were diagnosed with VTE after reminder was added ( 1.1 vs. $0.3 \%, p=0.001$ ). However, in the subset of critical medical care service, including 53 patients, the rate of pro- phylaxis was not significantly increased (63 vs. $79 \%$, $p=0.17)^{52}$

These studies suggest electronic reminders to be an effective way of increasing the rate of adherence to VTE prophylaxis in medical-surgical patients; however, they provide limited data on the efficacy in critically ill patients.

In summary, compliance with thromboprophylaxis is crucial for critically ill patients. The ideal strategies to improve the compliance should be effective, practical, and sustainable. Routine measures, such as VTE prophylaxis, are easily forgotten in the dynamic and evolving clinical situation found in the ICU. Physician education, use of care pathways, and electronic

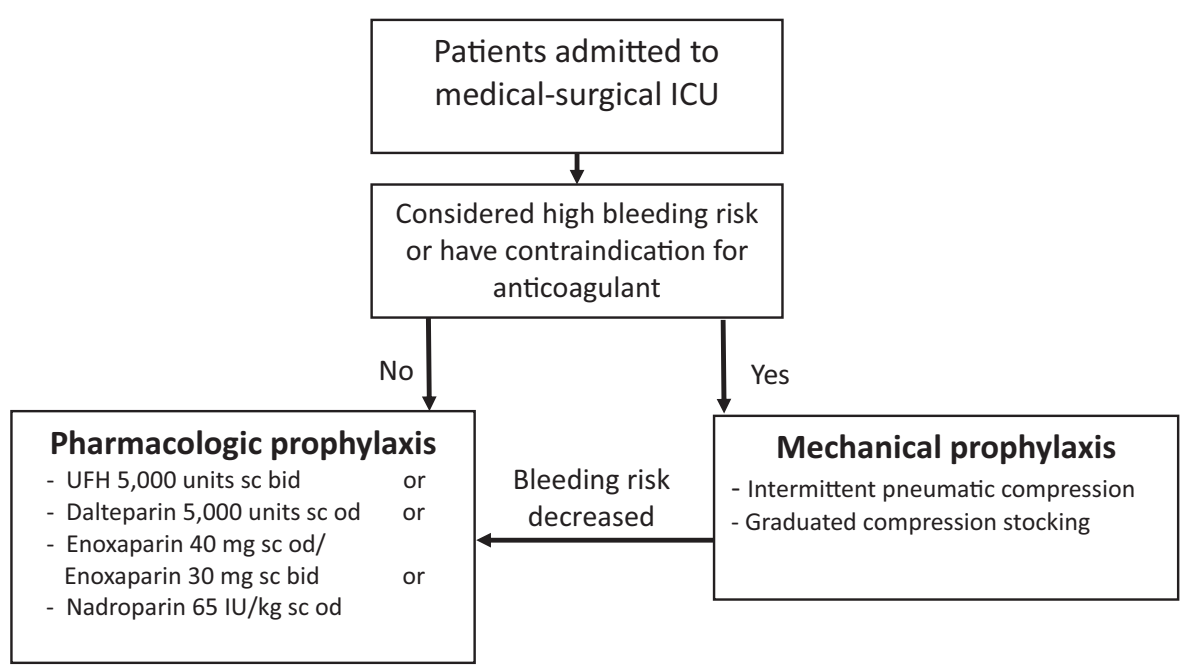

Fig. 1 Summary of venous thromboembolism (VTE) prophylaxis in intensive care unit (ICU). bid, twice a day; od, once daily; sc, subcutaneous; UFH, unfractionated heparin, IU, international units. 
reminders and tools such as a QRC are effective strategies to improve the VTE compliance.

\section{Conclusion}

VTE prophylaxis is a standard of care in critically ill patients. Omission of prophylaxis is associated with poorer outcomes. UFH and LMWH significantly decrease VTE rates compared with placebo. LMWH might be superior to UFH in terms of reductions in PE. Assessment of the bleeding risk for an individual patient is crucial. If the risk of bleeding is excessive, mechanical prophylaxis should be considered (-Fig. 1). IPC has better evidence than GCS alone. Strategies to improve thromboprophylaxis compliance include physician education, electronic order sets and reminders, and a QRC.

\section{References}

1 Moser KM, LeMoine JR, Nachtwey FJ, Spragg RG. Deep venous thrombosis and pulmonary embolism. Frequency in a respiratory intensive care unit. JAMA 1981;246(13):1422-1424

2 Geerts W, Cook D, Selby R, Etchells E. Venous thromboembolism and its prevention in critical care. J Crit Care 2002;17(2):95-104

3 Wilasrusmee C, Kiranantawat K, Horsirimanont S, et al. Deep venous thrombosis in surgical intensive care unit: prevalence and risk factors. Asian J Surg 2009;32(2):85-88

4 Angral R, Islam MS, Kundan S. Incidence of deep vein thrombosis and justification of chemoprophylaxis in Indian patients: a prospective study. Bangladesh Med Res Counc Bull 2012;38(2):67-71

5 Cade JF. High risk of the critically ill for venous thromboembolism. Crit Care Med 1982;10(7):448-450

6 Ribic C, Lim W, Cook D, Crowther M. Low-molecular-weight heparin thromboprophylaxis in medical-surgical critically ill patients: a systematic review. J Crit Care 2009;24(2):197-205

7 Khouli H, Shapiro J, Pham VP, et al. Efficacy of deep venous thrombosis prophylaxis in the medical intensive care unit. J Intensive Care Med 2006;21(6):352-358

8 Cook D, Crowther M, Meade M, et al. Deep venous thrombosis in medical-surgical critically ill patients: prevalence, incidence, and risk factors. Crit Care Med 2005;33(7):1565-1571

9 Ho KM, Chavan S, Pilcher D. Omission of early thromboprophylaxis and mortality in critically ill patients: a multicenter registry study. Chest 2011;140(6):1436-1446

10 Lilly CM, Liu X, Badawi O, Franey CS, Zuckerman IH. Thrombosis prophylaxis and mortality risk among critically ill adults. Chest 2014;146(1):51-57

11 Kapoor M, Kupfer YY, Tessler S. Subcutaneous heparin prophylaxis significantly reduces the incidence of venous thromboembolic events in the critically ill. Crit Care Med 1999;27(Suppl 12):A69

12 Fraisse F, Holzapfel L, Couland JM, et al; The Association of NonUniversity Affiliated Intensive Care Specialist Physicians of France. Nadroparin in the prevention of deep vein thrombosis in acute decompensated COPD. Am J Respir Crit Care Med 2000;161(4, Pt 1):1109-1114

13 Shorr AF, Williams MD. Venous thromboembolism in critically ill patients. Observations from a randomized trial in sepsis. Thromb Haemost 2009;101(1):139-144

14 Alhazzani W, Lim W, Jaeschke RZ, Murad MH, Cade J, Cook DJ. Heparin thromboprophylaxis in medical-surgical critically ill patients: a systematic review and meta-analysis of randomized trials. Crit Care Med 2013;41(9):2088-2098

15 Kahn SR, Lim W, Dunn AS, et al; American College of Chest Physicians. Prevention of VTE in nonsurgical patients: Antithrombotic Therapy and Prevention of Thrombosis, 9th ed: American
College of Chest Physicians Evidence-Based Clinical Practice Guidelines. Chest 2012;141(2, Suppl):e195S-e226S

16 Plott RT, Wagner RF Jr, Tyring SK. Iatrogenic contamination of multidose vials in simulated use. A reassessment of current patient injection technique. Arch Dermatol 1990;126(11):1441-1444

17 Bruguera M, Saiz JC, Franco S, et al. Outbreak of nosocomial hepatitis $C$ virus infection resolved by genetic analysis of HCV RNA. J Clin Microbiol 2002;40(11):4363-4366

18 De A, Roy P, Garg VK, Pandey NK. Low-molecular-weight heparin and unfractionated heparin in prophylaxis against deep vein thrombosis in critically ill patients undergoing major surgery. Blood Coagul Fibrinolysis 2010;21(1):57-61

19 Cook D, Meade M, Guyatt G, et al; PROTECT Investigators for the Canadian Critical Care Trials Group and the Australian and New Zealand Intensive Care Society Clinical Trials Group. Dalteparin versus unfractionated heparin in critically ill patients. $\mathrm{N}$ Engl J Med 2011;364(14):1305-1314

20 Goldhaber SZ, Kett DH, Cusumano CJ, et al. Low molecular weight heparin versus minidose unfractionated heparin for prophylaxis against venous thromboembolism in medical intensive care unit patients: A randomized controlled trial. J Am Coll Cardiol 2000;35 (Suppl):325A

21 Connolly SJ, Ezekowitz MD, Yusuf S, et al; RE-LY Steering Committee and Investigators. Dabigatran versus warfarin in patients with atrial fibrillation. N Engl J Med 2009;361(12):1139-1151

22 Patel MR, Mahaffey KW, Garg J, et al; ROCKET AF Investigators. Rivaroxaban versus warfarin in nonvalvular atrial fibrillation. N Engl J Med 2011;365(10):883-891

23 Granger CB, Alexander JH, McMurray JJ, et al; ARISTOTLE Committees and Investigators. Apixaban versus warfarin in patients with atrial fibrillation. N Engl J Med 2011;365(11):981-992

24 Giugliano RP, Ruff CT, Braunwald E, et al; ENGAGE AF-TIMI 48 Investigators. Edoxaban versus warfarin in patients with atrial fibrillation. N Engl J Med 2013;369(22):2093-2104

25 Goldhaber SZ, Leizorovicz A, Kakkar AK, et al; ADOPT Trial Investigators. Apixaban versus enoxaparin for thromboprophylaxis in medically ill patients. N Engl J Med 2011;365(23):2167-2177

26 Cohen AT, Spiro TE, Büller HR, et al; MAGELLAN Steering Committee. Rivaroxaban for thromboprophylaxis in acutely ill medical patients. N Engl J Med 2013;368(20):1945-1946

27 Decousus H, Tapson VF, Bergmann JF, et al; IMPROVE Investigators. Factors at admission associated with bleeding risk in medical patients: findings from the IMPROVE investigators. Chest 2011; 139(1):69-79

28 Agnelli G, Piovella F, Buoncristiani P, et al. Enoxaparin plus compression stockings compared with compression stockings alone in the prevention of venous thromboembolism after elective neurosurgery. N Engl J Med 1998;339(2):80-85

29 Limpus A, Chaboyer W, McDonald E, Thalib L. Mechanical thromboprophylaxis in critically ill patients: a systematic review and meta-analysis. Am J Crit Care 2006;15(4):402-410, discussion, 411-412

30 Zhang C, Zeng W, Zhou H, et al. [The efficacy of intermittent pneumatic compression in the prevention of venous thromboembolism in medical critically ill patients]. Zhongguo Wei Zhong Bing Ji Jiu Yi Xue 2011;23(9):563-565

31 Arabi YM, Khedr M, Dara SI, et al. Use of intermittent pneumatic compression and not graduated compression stockings is associated with lower incident VTE in critically ill patients: a multiple propensity scores adjusted analysis. Chest 2013;144(1):152-159

32 Vignon P, Dequin PF, Renault A, et al; Clinical Research in Intensive Care and Sepsis Group (CRICS Group). Intermittent pneumatic compression to prevent venous thromboembolism in patients with high risk of bleeding hospitalized in intensive care units: the CIREA1 randomized trial. Intensive Care Med 2013;39(5): $872-880$

33 Decousus H, Leizorovicz A, Parent F, et al. A clinical trial of vena caval filters in the prevention of pulmonary embolism in patients 
with proximal deep-vein thrombosis. Prévention du Risque d'Embolie Pulmonaire par Interruption Cave Study Group. N Engl J Med 1998;338(7):409-415

34 Group PS; PREPIC Study Group. Eight-year follow-up of patients with permanent vena cava filters in the prevention of pulmonary embolism: the PREPIC (Prevention du Risque d'Embolie Pulmonaire par Interruption Cave) randomized study. Circulation 2005; 112(3):416-422

35 Sarosiek S, Crowther M, Sloan JM. Indications, complications, and management of inferior vena cava filters: the experience in 952 patients at an academic hospital with a level I trauma center. JAMA Intern Med 2013;173(7):513-517

36 Keane MG, Ingenito EP, Goldhaber SZ. Utilization of venous thromboembolism prophylaxis in the medical intensive care unit. Chest 1994;106(1):13-14

37 Ryskamp RP, Trottier SJ. Utilization of venous thromboembolism prophylaxis in a medical-surgical ICU. Chest 1998;113(1):162-164

38 Cook D, Attia J, Weaver B, McDonald E, Meade M, Crowther M. Venous thromboembolic disease: an observational study in medical-surgical intensive care unit patients. J Crit Care 2000;15(4): 127-132

39 Muscedere JG, Heyland DK, Cook D. Venous thromboembolism in critical illness in a community intensive care unit. J Crit Care 2007; 22(4):285-289

40 Robertson MS, Nichol AD, Higgins AM, et al; VTE Point Prevalence Investigators for the Australian and New Zealand Intensive Care Research Centre; Australian and New Zealand Intensive Care Society Clinical Trials Group. Venous thromboembolism prophylaxis in the critically ill: a point prevalence survey of current practice in Australian and New Zealand intensive care units. Crit Care Resusc 2010;12(1):9-15

41 Ge J, Li Y, Jin X, Zhou J. Venous thromboembolism risk assessment and thromboprophylaxis among hospitalized acute medical patients in China-the RAMP study. Thromb Res 2010;126(4):270-275

42 Al-Otair HA, Khurshid SM, Alzeer AH. Venous thromboembolism in a medical intensive care unit. The effect of implementing clinical practice guidelines. Saudi Med J 2012;33(1):55-60
43 Parikh KC, Oh D, Sittipunt C, Kalim H, Ullah S, Aggarwal SK; VOICE Asia Investigators. Venous thromboembolism prophylaxis in medical ICU patients in Asia (VOICE Asia): a multicenter, observational, cross-sectional study. Thromb Res 2012;129(4):e152-e158

44 Yamamoto T, Nakamura M, Kuroiwa M, Tanaka K. Current prevention practice for venous thromboembolism in Japanese intensive care units. J Anesth 2013;27(6):931-934

45 García-Olivares P, Guerrero JE, Galdos P, Carriedo D, Murillo F, Rivera A. PROF-ETEV study: prophylaxis of venous thromboembolic disease in critical care units in Spain. Intensive Care Med 2014;40(11):1698-1708

46 Boddi M, Barbani F, Abbate R, et al. Reduction in deep vein thrombosis incidence in intensive care after a clinician education program. J Thromb Haemost 2010;8(1):121-128

47 McMullin J, Cook D, Griffith L, et al. Minimizing errors of omission: behavioural reenforcement of heparin to avert venous emboli: the BEHAVE study. Crit Care Med 2006;34(3):694-699

48 Teixeira PG, Inaba K, Dubose J, et al. Measurable outcomes of quality improvement using a daily quality rounds checklist: twoyear prospective analysis of sustainability in a surgical intensive care unit. J Trauma Acute Care Surg 2013;75(4):717-721

49 DuBose JJ, Inaba K, Shiflett A, et al. Measurable outcomes of quality improvement in the trauma intensive care unit: the impact of a daily quality rounding checklist. J Trauma 2008;64(1):22-27, discussion 27-29

50 Dubose J, Teixeira PG, Inaba K, et al. Measurable outcomes of quality improvement using a daily quality rounds checklist: oneyear analysis in a trauma intensive care unit with sustained ventilator-associated pneumonia reduction. J Trauma 2010; 69(4):855-860

51 Kucher N, Koo S, Quiroz R, et al. Electronic alerts to prevent venous thromboembolism among hospitalized patients. N Engl J Med 2005;352(10):969-977

52 Mitchell JD, Collen JF, Petteys S, Holley AB. A simple reminder system improves venous thromboembolism prophylaxis rates and reduces thrombotic events for hospitalized patients1. J Thromb Haemost 2012;10(2):236-243 